\title{
The 2015 Dietary Guidelines for Americans: Irrelevant or Alarming? or Both?
}

What should you eat to stay healthy? This is a question that certainly benefits from an examination through an evolutionary framework, and even then the answers are far from clear. However, as far as federal nutrition guidance is concerned, there is no debate. A "healthy diet" is one that is lower in fat, saturated fat, and cholesterol, particularly from animal products, and higher in whole grains, vegetable oils, fiber, fruits, and vegetables [1]. Whatever else might be debated about diet-disease relationships with regard to an ancestral health model, it is clear a diet high in processed grains, vegetable oils, and out-of-season fruits and vegetables is not one human animals have been eating for much of their history. However, even those with alternative views on nutrition find it difficult to completely avoid the ripple effects of federal dietary guidance. The Dietary Guidelines for Americans (DGA) not only provide the scientific rationale and policy basis for all federal programs and practices related to nutrition, they also create a framework for beliefs that drives consumer demand, shapes how food manufacturers formulate products, and directs the work of healthcare professionals, food system reformers, and the media [2].

The creation of the 2015 DGA generated considerable amounts of media attention, public awareness, and legislative activity, with long-standing battles over meat and saturated fat joined by related concerns about sustainable diets and scientific rigor. The uproar surrounding the 2015 DGA demonstrates how, paradoxically, they are increasingly irrelevant to many as nutrition guidance, while they continue to extend their reach into the lives of all Americans. Here I provide a brief background into the policy process and historical context of the DGA, summarize key aspects of the controversy surrounding the creation of the 2015 DGA, outline how that policy compares to previous editions, and illustrate how the DGA continue to expand their scope so few Americans will be unaffected by them.

\section{DGA policy process and historical context}

Every five years, a new edition of the DGA are created in a two-step process. First, the U.S. Departments of Agriculture (USDA) and Health and Human Services (HHS) use an opaque inter-departmental mechanism to select a group of scientists to form the Dietary Guidelines Advisory Committee (DGAC). The DGAC creates a report that ostensibly provides a review of current scientific evidence to inform revisions to the next edition of the DGA. The DGA are then written by staff members at the USDA and HHS and may or may not be based on recommendations in the DGAC report [1]. In 2015, a media frenzy surrounded both the DGAC report and the final DGA. Both the DGAC and the two agencies involved in writing the final DGA were accused of being "unscientific" and injecting their own agendas into the documents under their jurisdiction. However, even though "science" is invoked at every turn in the DGA process, the policy reflects a history of dietary guidance as concerned with social issues as it is with science. To understand the controversy, it is helpful to place the DGA within a larger historical context.

In many different historical circumstances, when figures of authority have taken it upon themselves to tell people how to eat, matters of health were attached to moral concerns. With the rise of scientific inquiry, the authority to establish moral precepts about food and self-control previously granted to 
religion was transferred to science. For example, in the early 1800 s, as the social upheaval of rapidly increasing industrialization and waves of immigration rattled the nation, vegetarian ideologues such as Sylvester Graham blended Christian philosophy with science to address individual health and social ills; eating in a way that led to a healthy body would lead to social order as well [3]. Modern dietary guidance may reference nutrition science for its authority, but it is built on a framework of moral principles about prudence and restraint in eating that have existed for centuries.

The DGA are no exception, having been shaped by the social, economic, and political turmoil of the 1970s, a decade that brought protests, riots, assassinations, bombings, kidnappings, and Watergate into most American living rooms. Against this backdrop of civil unrest, Earl Butz's agricultural policies emphasized fencerow to fencerow planting of commodity crops-corn, wheat, and soy-as droughts in Russia and Africa caused widespread famine and raised Malthusian concerns about feeding a growing world. An energy crisis sent food prices skyrocketing, especially the cost of meat; during that decade, Meatless Mondays were about boycotting meat producers so they would lower their prices. Healthcare costs were also rising, and the 1964 Surgeon General's report on cigarettes and cancer suggested modifying individual behaviors could prevent chronic diseases and save money, diverting momentum from the development of a national health plan. Theories that animal fats caused heart disease offered a way for individuals to take charge of their own health by changing their dietary habits. At the same time, food scientists were improving techniques for turning corn and soybeans into substitutions for the meat and animal fats thought to contribute to heart disease. Tying all of these threads together and giving traction to a burgeoning environmental movement was the best-selling vegetarian cookbook, Diet for a Small Planet, which proclaimed avoiding meat could help feed the hungry across the globe, protect the environment, and prevent chronic disease. [2]

In February 1977, a Senate report called the U.S. Dietary Goals was issued, advising Americans, among other things, to "Decrease consumption of meat." As the first federal dietary guidance meant to prevent chronic disease, this report also carried forward ideological commitments of its creators; dietary changes emphasizing prudence and restraint were seen as the solution not only to health concerns, but to a wide array of social ills. Scientists and policymakers-as well as meat producers-protested. When the second edition of the Goals was released in December 1977, the wording was shifted to focus on saturated fat, rather than meat, not because the science against saturated fat was overwhelming, but because the science against meat was virtually non-existent [4]. Thus from the start, controversies over federal dietary guidance to prevent chronic disease centered around meat, scientific evidence about its health effects, and its relationship to the environment.

Over the history of the $D G A$, concerns about meat-eating continued to be couched in terms of avoiding saturated fat. For their part, meat producers began developing meat with less fat in it, even as the hypothesis that dietary saturated fat was central to the development of most chronic diseases developed some demonstrable holes [5]. With the arrival of the review process for the 2015 DGA, a problematic situation arose: Saturated fat had been used to make the case against meat-eating for over 35 years. Now not only did meat have less fat in it, the scientific evidence against saturated fat seemed 
to be weakening. Shifting the position on meat and saturated fat would contradict decades of earlier guidance, but the rationales to sustain that guidance were dwindling.

\section{Controversy over 2015 DGA}

In February of 2015, after many months of deliberation, the DGAC released their report. Using a twopronged argument, the report maintained the stance that Americans should limit meat consumption [6]. Eschewing the USDA's Nutrition Evidence Library (NEL), which was created to provide a rigorous, objective, and transparent way to evaluate nutrition science, the DGAC used "existing reports" to confirm saturated fat did indeed cause chronic disease, despite considerable recent evidence to the contrary [7]. By using systematic reviews and meta-analyses from outside sources, the DGAC made the task of tracking the process of evaluating the scientific evidence-difficult enough when the NEL is used-nearly impossible. In addition, the DGAC added a new dimension to "dietary health": sustainability. This gave the DGAC the opportunity to present the argument that, regardless of production methods, a dietary pattern that reduced meat consumption was both "more health promoting" and "associated with lesser environmental impact" [6].

History repeated itself as policymakers, meat producers, and scientists questioned the validity of the DGAC's claims. Even the Academy of Nutrition and Dietetics, the professional organization of registered dietitians, argued saturated fat should no longer be considered a dietary hazard [8]. A behind-thescenes email written by Alice Lichtenstein, the DGAC member in charge of the saturated fat guidance, suggests there was reason to doubt the soundness of the DGAC's rationale [9]. In it, Lichtenstein admits "there is no magic/data" for the numbers used in recommending saturated fat intake be restricted to $10 \%$ or $7 \%$ of calories [9]. In June 2015 , policymakers still alarmed about the DGAC report proposed a spending bill that would limit the scope of DGA guidance to matters of diet and nutrition and recommendations to only those supported by the best possible evidence [10]. Former members of the 2015 DGAC protested these proposed changes, presenting the ironic picture of a "scientific advisory committee" on "dietary guidance" arguing for the inclusion of poorly supported and outside-the-realmof-diet guidelines [11].

The controversy resulted in Secretary of Agriculture Bob Vilsack and Secretary of Health and Human Services Sylvia Burwell being called to account for the DGA process in a Congressional hearing [12]. Prior to the hearing, the two Secretaries pre-empted some of their Congressional critics by announcing sustainability issues would not be a consideration in the next DGA [12]. Beyond this, however, Vilsack and Burwell were asked to justify the existence of dietary guidance the public appeared to be ignoring. Representative Colin Peterson of Minnesota seemed to speak for a number of policymakers when he questioned the wisdom of even having federal dietary guidance: "I wonder why we are doing this" [12]. In her equivocal defense of the DGA, Burwell admitted, "We are on the wrong trajectory, but would the trajectory have been worse?" [12]. Burwell's question is impossible to answer, but certainly the DGA have not had the effect on health outcomes they were meant to have.

In light of the continuing concern over federal dietary guidance, in December 2015 Congress passed a spending bill that would affect the DGA in three ways: 1) It redefined the scientific standard to be used 
for the $D G A, 2$ ) it limited the scope of the $D G A$ to nutritional and dietary information, and 3) it provided funding for a National Academy of Medicine review of the process behind the creation of the DGA [13]. The new edition of the $D G A$, released the first week of January 2016, avoided having to conform to the first two provisions of the spending bill; however future editions will have to be consistent with these requirements. And although the National Academy of Medicine review is currently underway, in the small world of nutrition experts vetted by the federal government, there is some element of infinite regress in this course of action. Finding a balanced and impartial committee to review the process for creating a balanced and impartial committee is bound to raise familiar questions of bias and hidden agendas.

\section{DGA and its implications}

In the end, the 2015 DGA was much like all previous editions. The new DGA repeated guidance of years past, emphasizing whole grains, fruits and vegetables, low-fat and fat-free dairy, nuts, fish, and allowing lean meat. There were, however, a few changes. Dramatic-and potentially dangerous-limits on sodium for some subpopulations disappeared, although the general population is still limited to no more than a teaspoon of salt a day. This edition also advised that "added sugars" be limited to $10 \%$ of total calories, although naturally occurring sugars are not implicated [1]. Numerical limits on cholesterol were eliminated, but the DGA still advised "individuals should eat as little dietary cholesterol as possible" [1]. And despite rumors proclaiming the "low-fat era" is over [14], there was little in the DGA to warrant this claim. Although vegetable oils were now a food category and the lower limit on oils in the diet had shifted from no less than $20 \%$ of calories to no less than $25 \%$, the upper limit on dietary fat as a macronutrient remained at $35 \%$ of calories, as it had been for the past decade [1]. As for meat, it did not disappeared altogether, but the DGA recommend "lower intakes of meats, including processed meats," lumping meat into the same category as sugar-sweetened food and refined grains [1].

What was most notable about the new $D G A$, however, was the expanded call for changing social norms around food to conform with DGA recommendations. The call for "aligning with the Guidelines" asserted that "health professionals, communities, business and industries, organizations, governments and other segments of society" could work together to "influence individual decisions, and ultimately social and cultural norms and values to align with the Dietary Guidelines" [1]. The effort to have all sectors of society enforce an individual's right to eat what the DGA have determined is best for everyone should be of concern to all in the ancestral health community. A push for a nationwide "alignment" with the DGA will affect policy-making, workplace wellness efforts, and insurance premiums in ways that may penalize those who choose alternative approaches to dietary health and further limit the options of those with too few resources to "opt out" of programs and practices linked to federal dietary guidance.

Nutrition policy is influenced by many factors; nutrition science is only one of a variety of forces that has shaped current dietary guidance. This suggests that organizations or individuals who would like to see the food-health system change to include an evolutionary perspective on dietary health should attend not just to the science of the $D G A$, but to its politics. Just as monoculture crops have taken over the 
agricultural landscape, monoculture nutrition is threatening to take over the food and health landscape. Creative and sustained resistance-in ways big and small-is needed to counter the advancing spread of the $D G A^{\prime}$ s version of dietary health.

\section{References}

1. U.S. Department of Health and Human Services and U.S. Department of Agriculture. $2015-2020$ Dietary Guidelines for Americans. $8^{\text {th }}$ Edition. December 2015. Available from https://health.gov/dietaryguidelines/2015/resources/2015-2020 Dietary Guidelines.pdf

2. Broad G, Hite A. Nutrition Troubles. Gastronomica. 2014 Fall; 14(3): 5-16. doi: $10.1525 /$ gfc.2014.14.3.5

3. Coveney J. Food, morals, and meaning: The pleasure and anxiety of eating. 2nd ed. New York: Routledge; 2006.

4. Oppenheimer GM, Benrubi ID. McGovern's Senate Select Committee on Nutrition and Human Needs versus the: meat industry on the diet-heart question (1976-1977). Am J Public Health. 2014;104(1):5969. doi:10.2105/AJPH.2013.301464.

5. Lawrence GD. Dietary Fats and Health: Dietary recommendations in the context of scientific evidence. Adv Nutr. 2013;4(3):294-302. doi:10.3945/an.113.003657.

6. Dietary Guidelines Advisory Committee. Scientific report of the 2015 Dietary Guidelines Advisory Committee. Washington, DC: US Dept of Health and Human Services and US Dept of Agriculture; 2015. Available from https://health.gov/dietaryguidelines/2015-scientific-report/pdfs/scientific-report-of-the2015-dietary-guidelines-advisory-committee.pdf

7. Achterberg C. Rigorous science must decide Dietary Guidelines to combat health epidemic. Roll Call. 2015 Oct 22. Available from http://www.rollcall.com/news/home/dietary-guidelines-must-be-basedon-rigorous-science-to-help-americans-combat-health-epidemics\#sthash.9KRUlqUU.dpuf

8. Tuma, PA. Comments on the Scientific Report of the 2015 Dietary Guidelines Advisory Committee. Academy of Nutrition and Dietetics. 2015 May 8. Available from http://www.eatrightpro.org/resource/news-center/on-the-pulse-of-public-policy/regulatorycomments/dgac-scientific-report

9. Heimlich, PM. Part 2 of 2 response to my 11/18/15 FOIA request re: 2015 US DGAC members Barbara Millen, Alice Lichtenstein, Frank Hu. 2016 May 12. Available from https://www.scribd.com/document/312807180/Part-2-of-2-response-to-my-11-18-15-FOIA-request-re2015-US-DGAC-members-Barbara-Millen-Alice-Lichtenstein-Frank-Hu

10. Appropriations Bill for Agriculture, Rural Development, Food and Drug Administration, and Related Agencies for the fiscal year ending Sept. 30, 2016 and for other purposes. House of Rep., 114th Cong., 1st Sess. (June 17, 2015). 
11. Lammi GG. Advisory committee's violation of federal law threaten credibility of 2015 Dietary Guidelines. Forbes. 2015 Dec 3. Available from http://www.forbes.com/sites/wlf/2015/12/03/advisorycommittees-violations-of-federal-law-threaten-credibility-of-2015-dietary-guidelines/\#632c4f373aa5

12. Hearing to review the development of the 2015 Dietary Guidelines for Americans: Hearing before the Comm. on Agriculture, House of Rep., 114th Cong., 1st Sess. (Oct. 7, 2015).

13. Consolidated Appropriations Act of 2015, Pub. L. No. 114-113, 129 Stat. 2280 (Dec. 18, 2015).

14. Hares, EP. New Dietary Guidelines remove restriction on total fat and set limit for added sugars but censor conclusions of the scientific advisory committee. Harvard T.H. Chan School of Public Health. 2016 Jan 7. Available from https://www.hsph.harvard.edu/nutritionsource/2016/01/07/new-dietaryguidelines-remove-restriction-on-total-fat-and-set-limit-for-added-sugars-but-censor-conclusions/ 